\title{
Ageing at home? Meeting housing, health and social needs
}

\author{
Jill Stewart \\ Social Work and Counselling Department, Faculty of Education and Health, \\ University of Greenwich, London, UK \\ Rachel Crockett \\ Centre for Positive Ageing, University of Greenwich, London, UK \\ Jim Gritton \\ Social Work and Counselling Department, Faculty of Education and Health, \\ University of Greenwich, London, UK \\ Brendon Stubbs \\ School of Health and Social Care, University of Greenwich, London, UK, and \\ Ann Pascoe \\ Carer and Founder/Director of Dementia Friendly Communities CIC, \\ Helmsdale, UK
}

\begin{abstract}
Purpose - The purpose of this paper is to consolidate the range of issues relevant to owner occupiers who age in place and to offer an initial overview of how effective partnerships can respond to and meet the changing needs of housing, health and social care of our ageing population.

Design/methodology/approach - Issues affecting older people's changing needs are considered holistically and considered in terms of how partnerships can be enhanced to develop improved services in the future.

Findings - Most owners wish to stay in their own homes for as long as possible and it can be costeffective to do so; however, we need to look at new and innovative ways of developing and providing front-line services to enhance health and safety in the home, but also quality of life and wellbeing such as combating loneliness and isolation. However, although there are examples of evidence-based good practice, service provision is variable and there is a risk that many older home owners may miss out on services for which they may are eligible. With this in mind, it may be helpful to develop a new framework where one key practitioner holds responsibility to consolidate and coordinate the range of local services available as a package that offers a range of housing, health and social care services. Originality/value - There are currently many policy and practice gaps in older owner occupier's housing conditions and suitability to meet their changing needs. This paper has a particular starting point in housing, and how other personal or technological services can help support independence for as long as possible and adapt to the owner-occupier's changing health and social care needs as they age in place. The authors emphasise the importance of sharing evidence-based good practice partnerships.
\end{abstract}


Life expectancy is rising across the world and with this comes morbidity changes (Salomon et al., 2012) presenting challenges across policy areas, including for housing. The links between housing, health and social care are well established (WHO, 2007; Department of Health, 2010; Marmot et al., 2010). However, despite more of us ageing in our own homes there is a paucity of research considering how housing maintenance and repair, as well as additional health and social care challenges, can be effectively met. Evidence demonstrates that it is not only cost effective with savings to health and social care services if we intervene early (Building Research Establishment (BRE) and Chartered Institute of Environmental Health (CIEH), 2008) but also appropriately tailored partnership working can substantially affect the quality of life of home owners as they age in place (Allan, 2005).

Partnerships here involve not only statutory and voluntary services, but also the person ageing at home and - where applicable - their carer and families who may or may not live with them. This creates numerous layers of complexity when looking at how best to provide home adaptations and appropriately tailored care and wider services. As the Birmingham Policy Commission (2014) has recently found, the experience of ageing is individual, complex, culturally and socio-economically varied and long term for all of us and there can be tensions between decisions around need and wants. Indeed it is the experience of some of the authors that home owners' wishes can be overlooked by well-meaning organisations who are struggling to make best use of their limited resources. These partnerships also include the older person, and - where applicable - co-habiting family members (it is their home too) as well as the wider family and friends. There is a risk that the language of professionals (service user, client or even customer) risks creating tensions and reducing choices to the home owner.

In recognition of some of the gaps and potential for growth in suitability of services, this paper presents some of the existing research and evidence supporting the need for more effective partnerships working to meet the needs of an ageing population remaining in their own homes as a basis for supporting further research. It considers those who are becoming increasingly vulnerable as they age, for example following loss of a partner, onset of dementia or declining physical health, etc., yet choose not to go into supported housing, or for whom there is no suitable supported housing provision available locally. Numbers falling into this category remain difficult to quantify.

\section{Why focus on owner occupiers?}

Private sector housing stock is a major asset holding substantial capital/equity and is often seen in terms of its investment potential rather than as a key social determinant of health offering a living environment that is secure and safe, and where appropriately tailored services can be provided. The private sector housing renewal budget ceased in 2011 (Wilson, 2011) and whilst its effectiveness in maintaining and improving health was never fully evaluated, a range of grants helped maintain, repair and improve the nation's housing stock and reduce pressures elsewhere in housing demand to some extent. Local authorities generally had inadequate staff and financial resources to deliver an effective system. Some grants (including small and rapidly processed grants) were targeted towards client need (Groves and Sankey, 2005) and were quick and easy to administer, sometimes through Home Improvement Agencies as a form of "soft regulation". This set the scene for a greater focus on client need than property management and offered viable partnerships and access to other services. However, engaging with private financiers to deliver an alternative to grant assistance has proven difficult (Groves and Sankey, 2005) and anecdotal evidence suggests that many find schemes such as 
equity release although this remains a governmental preference. However, there has since been a lack of continuity in research as to the effectiveness of local partnership-based interventions. This arises both from continued organisational change, notably the new public health and commissioning arrangement, but also in terms of how we develop and deliver improvements in service delivery, particularly at a time of such rapid technological change. There is a need to consolidate and replicate/adapt good practice more widely, particularly against a backdrop of decline in capital resource. In addition, as our population continues to age, our health and social care needs become more complex. Ageing associated increases in chronic diseases such as dementia require individual and specialist responses.

It would of course be beneficial for one person to be able to represent the home owner and their livein family members so that choice is maintained as far as possible and support or funding is not offered on condition that it has to be given in a way that suits the organisation, who may themselves be constrained by legislation and funding arrangements. Factoring in earlier pathways to enable choices may help shift a culture towards one of more self-reliance (for those able to fund their own works and services) and active decision making that suits the home owner and enables them to live in their own home for as long as possible. What is key is that we can live in our homes in our own way, not the way someone tells us we have to do it. So, as an early intervention, those appropriately tailored partnerships would certainly substantially affect the quality of our lives as we age. The existing family home may offer safe haven but may also have negative features. The house may be deteriorating in condition and may have lacked maintenance and repair for a period of time; it may be too large for a single lone person and expensive to run, especially heating; existing facilities may prove increasingly inappropriate as the occupier ages and becomes more frail.

Home adaptation solutions can sometimes be both aesthetically unappealing, labelling and a constant reminder of the owner's conditions. In many cases more choice could be given in home adaptations as well as in care and wider activity services available to us as we age in place and we attempt to draw from our professional and personal experiences in offering initial thoughts of a future framework in further discussion. Owner occupiers have a vested interest in their homes and will work in partnership if sense is used and not a "rigid" one size fits all. It is the experience of some of the authors that home owners' wishes can be overlooked by well-meaning organisations. Appropriate resources are already built-in in a care home setting, but there is inequity across tenures and we need to consider how to facilitate comparable services for those in private sector housing.

\section{Effective partnership working}

In recent years there had been a marked shift towards the effectiveness of front-line strategies and interventions (see, e.g. Stewart, 2013, cited on the NICE evidence base in 2014). However anecdotal evidence demonstrates that, with the wider complications presented by someone ageing in their home, partnerships can be erratic and ad hoc with no effective form of guidance to help assist and support those varied personnel working at the front line, in situations that are often highly complex and rapidly changing.

In order to facilitate more effective partnership working, developing an understanding of what Rittel and Webber (1973) refer to as "wicked" problems - or "messes" in Ackoff's (1974) parlance - may be useful. "Wicked" problems tend to have many interlocking causes and multiple stakeholders; they are 
hard to define, immune to "right" answers and thus resistant to "one size fits all" solutions. To make matters worse, attempts to implement a solution may inadvertently exacerbate the problem as stakeholders may have different perspectives and competing needs which cannot be satisfied by a neat and tidy solution. Viewed against this definition, ageing in place is clearly a very "wicked" issue.

Managing the needs of ageing in place, addressing the housing, health and social care needs of those with early onset dementia and whose condition will invariably decline, with or without support from family or community, is undoubtedly a "wicked" issue. As such, it requires holistic thinking, a greater understanding of the issue and those affected by it, and how they are affected by it. However, such thinking demands a very different kind of leadership that not only promotes collaboration but also fosters trust across a range of organisational stakeholders where clients - or service users - are shared and resourced (Hunter, 2009). In order to achieve this, an appropriate toolkit of strategies and interventions is needed to help assure effective front-line service delivery in enhancing wellbeing and quality of life. Each intervention should contribute a bit more towards addressing inequality, promoting health and enhancing wellbeing and quality of life and multiple factors need to be considered, including demographic change and reorganisation of public health functions. This will require much greater emphasis on partnership working.

To further complicate proceedings, each organisation involved in addressing the needs of our older population, e.g. social workers, mental health services, environmental health and housing, has different functions and purposes, be they advocacy, support or more direct and "top down" interventions. These have to be balanced against the personal autonomy of the individual and the expectations of the family, such as re-housing elsewhere, with or without funding from the owner's savings and equity in the house. These issues may be further complicated by concerns regarding mental capacity, and (where applicable) the presence of Lasting Power of Attorney orders adds another layer of complexity to decision making.

\section{What, then, needs to be done?}

It is often more acceptable, across a variety of fronts, for owners to stay in their own homes for as long as possible. They may have a strong sense of security and familiarity, know the area and neighbours, and have their own space, privacy and belongings, including pets for company. Loss of their partner, who may well also have been their carer, can leave an enormous gap both in terms of loneliness but also in day-to-day living arrangements, such as cooking and cleaning. In terms of helping support a home owner to remain in their home, there are overlapping factors to consider. These include maintaining the physical condition of the property (enhancing both health and safety) as well as attending to the changing health and social care needs of the occupier (medical, wellbeing and quality of life).

However, there can be tensions between what the local authority may be "obliged" to deliver by way of statute and guidance and what the home owner desires and there may or may not be agreement. Existing homes will not have been designed to the standard of care homes and there is of course a disconnect. Again in the experience of some of the authors, some adaptations may be inappropriate and home owners may prefer to retain control over how their homes feel, making them cosy, liveable and without obtrusive features so that - where applicable - the rest of the family can continue living there as "normally" as possible but also that rapid adjustments are possible if the person's condition 
deteriorates. And also, what do they and their family members who live with them want from their home and for their wellbeing? When thinking through services, perhaps we should start somewhere new: what does an older person primarily need? Health Psychologists highlight the beneficial effects on health of good social support. Remaining at home helps maintain existing social support networks which can help maximise health outcomes. For example, Seeman et al. (2001) found that good social support at baseline was associated with better cognitive performance at follow-up 7.5 years later, and with greater wellbeing in older people experiencing chronic disease (Ferreira and Sherman, 2007). In contrast, social isolation has been associated with higher mortality rates in older people (Steptoe et al., 2013).

Funding in England is problematic and as our population continues to rise Age UK report that spending on social care services for older people has dropped by $£ 1.2$ billion (15.4 per cent) since 2010 . $£ 438$ million was transferred from the National Health Service (NHS) to local authorities but still leaving a shortfall of $f 760$ million. This is despite growing demand in older people aged 85 and over needing more care and funding has remained broadly stagnant since 2005 (O'Connor for Age UK, 2014). The Better Care Fund helps plug some gaps but substantial pressures remain and many local authorities are able only to assist the most vulnerable (O'Connor for Age UK, 2014). There is a need for further joint working in promoting both improvements in quality of life and the cost effectiveness of effective interventions more holistically across housing, health and social care for older people.

The Housing Health and Safety Rating System (HHSRS) helps us think through not just property management, but also the effect of issues on the vulnerability of the occupier (Office of the Deputy Prime Minister, 2006). HHSRS has also been pivotal in enabling us to think through options and calculate a range of savings to other health and social care sectors, such as for home accidents and the effects of cold housing (Building Research Establishment and Chartered Institute of Environmental Health, 2008). We also know that there are numerous "exported costs" of poor housing elsewhere, such as crime and accidents due to poor fire safety (see, e.g. Ambrose, 2001). Home accidents and fuel poverty are of increasing importance to an older and more vulnerable population. Older people need to spend more on heat as they are in the home longer and need elevated temperature to feel comfortable and stay healthy, but may struggle to meet higher fuel costs and there is an increasing body of research around the mental health effects of cold homes (see, e.g. Walker et al., 2013).

Routine maintenance and repairs may be left, may not be a priority and may therefore become more expensive longer term. Handyperson schemes can be helpful in appointing suitably qualified and trustworthy builders, who also understand the needs and concerns of older people and may work for those able and willing to pay for small scale works. Grant assistance may also be available in some cases. Some partnerships could be clearer about what is available locally, how to access the services and what it would cost and options for funding but the national picture is very erratic.

As people age, risks to health and safety are elevated. Of particular concern is the increased risk of falls since they are one of the leading causes of avoidable death across the world (WHO, 2007). Falls are often attributable to internal (e.g. reduced balance) or external risk factors (e.g. difficulty using the stairs or poor lighting). Adaptations to the environment may result in reductions in falls among older adults living in community dwellings (Pynoos et al., 2010). In addition, the indoor and outdoor built environment are known to influence levels of activity among older adults living in community 
dwellings and these require careful consideration to enable individuals to remain independent and not isolated (Rosenberg et al., 2013). Fire (and gas) safety is a potential hazard in all homes, but again risk can be greater when automatic fire (and carbon monoxide) detection is not factored into existing homes, rather than designed-in from early planning stages. In some areas, Fire Officers will assist with free advice and appliances.

Hazards and risks to the person can also be reduced by assistive technologies ("telecare") that are able to be factored into the property such as identifying if a door is opened at an unexpected time and raising an alarm, or person-centred in case the older person falls in the home or goes outside at an unexpected time, so triggering a call alarm so that help can be administered as quickly as possible. Developments in this field are rapid, subject of major research projects and expected to yield major savings to the NHS (Department of Health, 2011).

Preparing one's home for the future is important as needs not just change once, but continue to change for all who lived there; this can also helps prevent crisis. Thinking changes through can help a more personalised solution that can provide place and space for family wellbeing and not just meeting "bureaucratic" solutions or requirements that may be funded, although many of course do not have the option of choice. West of England Care and Repair has linked to a design centre where people are able to go and look at what is on offer (see www.wecr.org.uk/\#/home-design/4569694625). Other housing and social care organisations are seeking to provide more of a centre for services. However, all of this is very sporadic, local and down to chance of where one lives. Such centres may help promote a wider culture of preparing for the future.

Existing residential care homes already have many of these arrangements factored in. It may be that some of the opportunities available could be opened up to the wider home owning community who may not yet be ready for full-time living in a care home, or who are waiting for a suitable place, but who currently fall through the gaps of available provision.

Home Improvement Agencies have been pivotal in providing many services and support mechanisms which respond to complex issues in ageing in place. Extending these services with a new recommended framework where one practitioner becomes key in working in partnership (which includes family and friends) to help ensure the best package of services and activities, could make a real difference to quality of life and wellbeing. Indeed, as the Birmingham Policy Commission (2014) reminds us, older people want control and independence and there needs to be a careful balance in addressing risk, whilst meeting care and support. There is scope and potential to factor this into practice more effectively.

\section{Daily activities and counteracting loneliness}

Despite a "Big Society" and localism agenda, social capital is generally seen to be in decline with a subsequent loss of social care and support from the community. This has major implications for older people who are less likely to be able to play an active role in their community and may become increasingly isolated in their homes without regular company. Many services are minimal to keep costs down and social care providers may be able to offer basics only (such as meals and cleaning) that may offer little in the way of company or stimulation. Here there is huge scope to explore possibilities for 
how wider services can be built into packages of health and social care, whether or not the client is able to fund this either from savings or equity release.

Remaining at home helps one maintain existing social support networks. One of the key issues around dementia is that support networks tend to fail, i.e. family and friends stay away because of fear, myth, stigma and essentially because of their lack of understanding about dementia. Dementia friendly communities and dementia friends change all of this: it is in fact now a blend of primary care support (including effective home care, etc.) plus the dementia friendly community and dementia friends that will support the family to continue to live at home and to think about preparing for what the future will bring. Dementia friendly communities and dementia friends are encouraging social inclusion activities in a range of local venues, not just more formal day care centres that welcome everyone and may help to fill in gaps in with a demise in extended families and social capital generally. Lifestyle can have major implications for public health and older people. Physical inactivity is the fourth leading cause of mortality (World Health Organisation (WHO) and Commission on the Social Determinants of Health, 2013) and it is essential that environments are conducive to facilitating physical activity since higher levels of physical activity are associated with the prevention of the onset of disability and dependence in activities of daily living in older adults (Tak et al., 2013). In addition, there is convincing evidence that higher levels of physical activity are associated with a reduced risk of cognitive decline (Erickson et al., 2012) and a reduction in depressive symptoms (Bridle et al., 2012) in older adults living in community dwellings. In addition, physical activity is strongly implicated in reducing the risk of many of the leading causes of mortality in older adults (WHO and Commission on the Social Determinants of Health, 2013).

Diet is also essential in maintaining and promoting health and wellbeing and substantial evidence demonstrates the importance of a good diet (see, e.g. Kayani, 2009). Diet may be negatively affected by poverty, low esteem or general disinterest, and again it may be that an enhanced and planned local environment may help in having better local shops as well as "clubs" where people can both share company and nutritious and culturally acceptable food together (see, e.g. Kayani, 2009). It would be helpful to move beyond basic "meals on wheels" type provision to something adding more to quality of life and wellbeing. With a decline in social capital, and uncertainties over future funding for our ageing population, we need to look at new ways to "factor in" community (a growing body of research is available: see, e.g. Hartnett et al., 2013). Volunteering and assistive technologies can help plug some of the gaps. Volunteering has been shown to have positive wellbeing benefits both for the volunteer and service recipient and though invariably sporadic nationally, may offer other opportunities to older and isolated people to be able to participate more actively in their local communities. Altruistic attitudes, volunteering and informal helping can maintain life satisfaction and positive mental wellbeing in older age groups (Kahana et al., 2013). Older adults who volunteer report higher levels of wellbeing, regardless of the number, type of organisation or perceived benefit to others. Such research suggest that it would be beneficial to engage older people in a range of volunteer roles, and further research in this areas may help further enhance volunteering efforts (Morrow-Howell et al., 2003).

There is a real need to consolidate evidence examples and good practice of what works in addressing older people's changing needs, particularly those with dementia and there are successful examples across the country. Such initiatives offer a solution to loneliness and isolation as well as activities that 
support cognitive stimulation. In Kent and Medway, for example, one project focuses on jolting memories through multi-sensory stimulation through handling objects, such as carbolic soap and looking at old photographs to write stories (Pati, 2010). In Merseyside, a pilot project is using artistic therapy which again offers company alongside creative expression both for the person affected and their partner, whose needs often go unmet. Evaluation includes how feelings change and how the activities affect mood and communication in helping address some behavioural symptoms of dementia (Leeming, 2013). However many services tend to be for those already in care homes, and owner occupiers may risk missing out on some of the services available. Good broadband and internet connections, which can be particularly crucial in rural areas where more and more older people are living, help to plug social gaps, with many finding Skype particularly helpful. iPads (which do not have the same connotations as computers to older people) have been found to assist as they are "intuitive" to use. Numerous web sites offer advice. For example www.myageingparent.com suggests that Skype and FaceTime are a good way for keeping in touch and that being able to see each other has numerous advantages, such as visually checking another person's health and living conditions. iPads may also offer more active television watching, as well as engaging with YouTube clips for general entertainment, reminiscence or learning new skills. The Telecare Network Newsletter publishes regular updates:

(www.telecarelin.org.uk/_library/Resources/Telecare/Telecare_advice/Newsletter/Telecare_LIN_eN ewsletter_January_2014_Final.pdf and it is also helpful to refer to blogs such as $<$ http://ageinginnovators.org/for constant innovations>).

\section{Conclusion}

Much current literature, policy and practice seem to be mainly medical or about care homes, not frameworks to help people stay in their own homes if that is what they choose. A range of services and interventions are required to meet the changing needs of our growing older population. Services should be unique, responding to the ageing house as well as the ageing occupier with increasing needs and appropriate assistive technologies factored in. We need to honestly ask ourselves about the type of services we would like to have for the future, how they might be funded and how we find out what is available.

Such change requires organisational and cultural shifts at all levels, community/voluntary, statutory services, as well as wicked/messy issues The emerging services we are developing, offering and commissioning through the new public health and social care arrangements need to be demonstrably cost effective and add to quality of life, health and wellbeing. We need to incorporate assistive technologies, which already have recognised saving, and we need to find more innovative ways to promote quality of life and the ability to age in one's own home. Perhaps above all we need to be open minded to change and base what we do on research and evidence of what works, and why, so we can develop quality - and not last resort - services we would like to both deliver and potentially receive ourselves in our own lifetimes. This paper also seeks to raise awareness that health and social services, which includes all the satellite organisations connected to that world, need to intervene early on and work with home owners to ensure their homes are ready for their old age so that they can live at home for as long as possible which means care home or hospital admissions become crisis interventions only.

Such a consolidated framework would require a negotiated partnership with one practitioner pivotal in ensuring a drawing together of relevant services and activities to effectively and dynamically meet housing, health and social care needs. 


\section{References}

Ackoff, R. (1974), Redesigning the Future: A Systems Approach to Societal Problems, Wiley,

New York, NY.

Allan, T. (2005), "Private sector housing improvement in the UK and the chronically ill:

implications for collaborative working", Housing Studies, Vol. 20 No. 1, pp. 63-80.

Ambrose, P. (2001), "Living conditions and health promotion strategies", Journal of the Royal

Society for the Promotion of Health, Vol. 121 No. 1, pp. 9-15.

Birmingham Policy Commission (2014), The Report 2014: Healthy Ageing in the 21st Century:

the Best is Yet to Come, University of Birmingham, Birmingham.

Building Research Establishment (BRE) and Chartered Institute of Environmental Health (CIEH) (2008), Good Housing Leads to Good Health: A Toolkit for Environmental Health

Practitioners, $\mathrm{CIEH}$, London.

Bridle, C., Spangers, K., Patel, S., Atherton, N.M. and Lamb, S.E. (2012), "Effect of exercise on depression severity in older people: systematic review and meta-analysis of randomised controlled trials", British Journal of Psychiatry, Vol. 201 No. 3, pp. 180-185.

Department of Health (2010), Confident Communities: Brighter Futures, Developing a Framework for Wellbeing, HMSO, London.

Department of Health (2011), "Research and development work relating to assistive technology 2010-11: presented to parliament pursuant to section 22 of the chronically sick and disabled persons Act 1970 research and development work relating to assistive technology 2010-11", available at: www.gov.uk/government/uploads/system/uploads/attachment_data /file/215543/dh_127996.pdf 9 (accessed 21 March 2014).

Erickson, K.I., Weinstein, A.M. and Lopez, O.L. (2012), "Physical activity, brain plasticity, and Alzheimer's disease", Archives Medical Research, Vol. 43 No. 8, pp. 615-621.

Hunter, D. (2009), "Leading for health and wellbeing: the need for a new paradigm", Journal of Public Health, Vol. 31 No. 2, pp. 202-204.

Ferreira, V.M. and Sherman, A.M. (2007), "The relationship of optimism, pain and social support to well-being in older adultswith osteoarthritis", Aging and Mental Health, Vol. 11No. 1, pp. 89-98.

Groves, R. and Sankey, S. (2005), "Implementing new powers for private sector housing renewal", available at: www.jrf.org.uk/sites/files/jrf/1859354289.pdf (accessed 21 March 2014).

Hartnett, E., Minocha, S., Palmer, J., Petre, M., Evans, S., Middup, C.P., Dunn, K., Murphy, B., Heap, T. and Roberts, D. (2013), "Older people and online social interactions: an empirical investigation", The UKAIS International Conference on Information Systems (UKAIS), Worcester College, University of Oxford, Oxford, 18-20 March, available at: http:// oro.open.ac.uk/36591/1/paper12.pdf (accessed 24 March 2014).

Kahana, E., Bhatta, T., Lovegreen, L.D., Kahana, B. and Midlarsky, E. (2013), "Altruism, helping, and volunteering: pathways to well-being in late life", Journal of Aging and Health, Vol. 25 No. 1, pp. 159-187.

Kayani, N. (2009), "Food, health and wellbeing", in Stewart, J. and Cornish, Y. (Eds), Professional Practice in Public Health, Reflect Press Ltd, Exeter, pp. 265-278.

Leeming, C. (2013), "Express yourself", Inside Housing, Vol. 6, pp. 28-31, available at: www.insidehousing.co.uk/express-yourself/6529843.article (accessed 3 November 2014). Marmot, M.G., Allen, J., Goldblatt, P., Boyce, T., McNeish, D., Grady, M. and Geddes, I. (2010), Fair Society, Healthy Lives: Strategic Review of Health Inequalities in England Post-2010, The Marmot Review, London. 
Morrow-Howell, N., Hinterlong, J., Rozario, P. and Tang, F. (2003), "Effects of volunteering on the well-being of older adults", Journals of Gerontology Series B: Psychological Sciences and Social Sciences Sci, Vol. 58 No. 3, pp. S137-S145.

O'Connor, S. (2014), "Care in crisis: what's next for social care", available at: www.ageuk.org.uk/ latest-news/age-uk-publishes-damning-report-on-care-crisis/ (accessed 24 March 2014). Office of the Deputy Prime Minister (2006), "Housing health and safety rating system operating guidance", available at: www.gov.uk/government/uploads/system/uploads/attachment_ data/file/15810/142631.pdf (accessed 24 March 2014).

Pati, A. (2010), "Down Memory Lane", Inside Housing, available at: www.insidehousing.co.uk/ analysis/best-practice/down-memory-lane/6510305.article (accessed 21 March 2014).

Pynoos, J., Steinman, B.A. and Nguyen, A.Q. (2010), "Environmental assessment and modification as fall-prevention strategies for older adults", Clinics in Geriatric Medicine, Vol. 26 No. 4, pp. 633-644. Rittel, H. and Webber, M. (1973), "Dilemmas in a general theory of planning", Policy Sciences, Vol. 4 No. 2, pp. 155-169.

Rosenberg, D., Huang, D.L., Simonovich, S.d. and Belza, B. (2013), "Outdoor built environment barriers and facilitators to activity among midlife and older adults with mobility disabilities", The Gerontologist, Vol. 53 No. 2, pp. 268-279.

Salomon, J.A., Wang, H., Freeman, M.K., Vos, T., Flaxman, A.D., Lopez, A.D. and Murray, C.J.L. (2012), "Healthy life expectancy for 187 countries, 1990-2010: a systematic analysis for the global burden disease study 2010", The Lancet, Vol. 380 No. 9859, pp. 2144-2162.

Seeman, T.E., Lusignolo, T.M., Albert, M. and Berkman, L. (2001), “Social relationships, social support, and patterns of cognitive aging in healthy, high-functioning older adults: MacArthur studies of successful aging", Health Psychology, Vol. 20 No. 4, pp. 243-255. Steptoe, A., Shankar, A., Demakakos, P. and Wardle, J. (2013), "Social isolation, loneliness, and all-cause mortality in older men and women", Proceedings of the National Academy of Sciences, Vol. 110 No. 15, pp. 5797-5801.

Stewart, J. (Ed.) (2013), Effective Strategies Interventions: Environmental Health and the Private Housing Sector, $\mathrm{CIEH}$, London.

Tak, E., Kuiper, R., Chorus, A. and Hopman-Rock, M. (2013), "Prevention of onset and progression of basic ADL disability by physical activity in community dwelling older adults: a meta-analysis", Ageing Research Reviews, Vol. 12 No. 1, pp. 329-338.

Walker, R., Thomson, H. and Liddell, C. (2013), "Fuel Poverty 1991-2012: commemorating 21 years of action, policy and research", available at: http://fuelpoverty.eu/wp-content/ uploads/2013/03/Fuel-poverty-anniversary-booklet.pdf (accessed 24 March 2014). Wilson,W. (2011), "Assistance to improve/repair private sector housing: SN/SP/1617 4 April 2011 house of commons library 2011", available at: file://C:/Documents\%20and\%20Settings/ Homeuser/My\%20Documents/Downloads/SN01617\%20(1).pdf (accessed 21 March 2014). World Health Organisation (WHO) and Commission on the Social Determinants of Health (2013), "Closing the gap in a generation: health equity through action on the social determinants of health", available at: http://whqlibdoc.who.int/publications/2008/9789241563703_eng.pdf (accessed 14 March 2014).

WHO (2007), "WHO global report on falls prevention in older age. WHO. ISBN 9789241563536 WHO (2014). 10 facts on physical activity", available at: www.who.int/features/factfiles/ physical_activity/en/ (accessed 14 March 2014). 


\section{Further reading}

Andrews, J., Molyneux, P., Swan, A. and Bell, P. (2013), "Dementia: finding housing solutions", available at: www.housing.org.uk/publications/browse/dementia-finding-housingsolutions (accessed 29 June 2013).

Boyd, R. and Stevens, J.A. (2009), "Falls and fear of falling: burden, beliefs and behaviours", Age Ageing, Vol. 38 No. 4, pp. 423-428.

Care and Repair (2014), "On the cusp? Integration of housing, care and health for older people", available

at: www.careandrepair-england.org.uk/pdf/pr_11_03_2014.pdf (accessed 20 March 2014).

Care and Repair England (2012), "Making your home a better place to live with dementia", available at: www.careandrepair-england.org.uk/homefromhospital/pdf/live_with_dementia.pdf (accessed 26 June 2013).

Croucher, K., Hicks, L. and Jackson, K. (2006), Housing with Care for Later Life: A Literature Review, Joseph Rowntree Foundation, York.

Davidson, M., Roys, M., Nicol, S., Ormandy, D. and Ambrose, P. (2009), The Real Cost of Poor Housing, IHS BRE Press, Bracknell.

Donald, I.P. (2009), "Housing and health care for older people", Age and Ageing, Vol. 38 No. 4, pp. 364-367.

Means, R. (2007), "Safe as houses? Ageing in place and vulnerable older people in the UK", Social Policy and Administration, Vol. 41 No. 1, pp. 65-85.

\section{About the authors}

Dr Jill Stewart's environmental health and housing career started in local government, leading to her current post as a Senior Lecturer in the Psychology, Social Work and Counselling Department, Faculty of Education and Health at the University of Greenwich. She teaches at undergraduate and postgraduate levels across housing, public health and social work subject areas. She is a Corporate Member of the Chartered Institute of Environmental Health (CIEH), a Member of the Chartered Institute of Housing and a Fellow of the Royal Society for Public Health. Her main research interests include evidence-based practice and the effectiveness of front-line strategies and interventions and as such she has pioneered housing evidence bases online. Dr Jill Stewart is the corresponding author and can be contacted at: j.l.stewart@greenwich.ac.uk

Dr Rachel Crockett is a Registered Health Psychologist. She is currently a Senior Research Fellow in the Centre for Positive Ageing at the University of Greenwich and has previously worked at a number of universities including the King's College London and the University of Cambridge. Her research interests are focused on the prevention of serious disease through health behaviour change and population level and environmental changes to promote healthier behaviour such as healthy eating and physical activity. These interests were stimulated bya Wellcome Trust Funded Fellowship at the Parliamentary Office for Science and Technology in 2007 and subsequently her research has been underpinned by a concern to ensure that it is relevant to healthcare practitioners and policy makers.

Jim Gritton was a Probation Officer originally by training. Jim Gritton enjoyed a successful management career in the National Probation Service rising to an Assistant Chief Officer in Surrey. He left public service in 2003 to co-found a small management consultancy specialising in leadership and management development. An expert in online learning, he taught at the Open University Business School before joining the University of Greenwich in 2011. He teaches a wide range of leadership and 
management courses at both undergraduate and master's levels in health and social care. He is pursuing a Doctorate in Education and researching leadership development in 3D immersive virtual worlds. He currently chairs an international research group on experiential learning in virtual worlds.

Brendon Stubbs qualified as a Physiotherapist over ten years ago and is currently half way through a PhD. Current research themes are the promotion physical activity in several populations, falls prevention, reducing the physical health disparity in people with mental illness and a range of topics related to dementia. Brendon frequently presents at National conferences and earlier this year gave a key note speech at an international conference in Utrecht detailing his work on the barriers and facilitators to physical activity participation of physical activity in community dwelling older adults with dementia (currently under review). Brendon has published over 15 articles in international journals since the start of 2013.

Ann Pascoe was in business (Managing Director) before retiring to Scotland in 2000. In 2005 her husband Andrew was diagnosed with vascular dementia and since they lived in a remote rural Highlands' hamlet with no support, as a lone carer she began campaigning for change. Ann is now a National and International Speaker on dementia. Her main interests are around the frail elderly, carer stress and technology/housing issues. Ann advises on and regularly does workshops - at undergraduate and master's levels - around carer support/stress and dementia friendly communities for health boards, businesses and academic institutions. 